\title{
TOWN PLANNING AND URBAN CONCENTRATION
}

\begin{abstract}
HE admirable way in which the evacuation plans have been carried out in the present emergency should not lead us to overlook the importance, when the time comes, for considering the re-planning or further development of our cities on lines designed to minimize such disturbance or upheavals, and the problems which urban concentration presents in civil defence aro further reason for attention to this question at the first opportunity. The paper in which Dr. Thomas Adams discussed some economic aspects of urban concentration before Section $F$ (Economics) at the Dundee meeting of the British Association on the very eve of the evacuation could scarcely bo surpassed as an analysis of the principles involved.
\end{abstract}

Dr. Adams pointed out that concentration of industry, economic activities and population in urban centres is essential - in order to secure the economic benefits to bo derived from scientific progress, and need not militate against social welfare. The advantages of concentration may, however, be impaired by excess or malformation, and in many urban centres such excessive concentration has caused intolerable congestion of traffic, impaired industrial efficiency and overerowded building dovelopment. The most powerful force in causing urban concentration is the existence and potentialities for dovelopment of transport facilities, allied with certain favourable qualities in the natural situation, and the planning and control of these facilities are essential to prevent excess.

That New York and London and certain other cities have become too unwieldy to perform their functions efficiently is probably due to their development being artificially promoted, by political agencies and vested interests, beyond that which could occur under the normal play of economic forces. The proper way to eliminate excessive concentration is to promote recentralization on sites with competitive attractions. Even in regard to vulnerability, Dr. Adams does not advocate an excessive attempt to restrict artificially the location and distribution of industry. He argues that if a city, even of the size of London, as a piece of civic machinery, is perfectly designed to perform its functions as an industrial and distribution centre, and if the residue is diffused into compact neighbourhoods and integrated with its industrial areas so as to reduce distances between homes and workplaces, the true solution is to construct adequate defences or even to face evacuation in war time at any cost.

Dr. Adams argues that the steady flow and free movement of street traffic are essential for economic efficiency, and urban areas should be planned or replanned to provide the space required. Further, if the main transport facilities are properly planned and controlled, artificial restriction of the location and distribution of industry should scarcely be required, and provision of ample space for locomotion purposes should simultaneously meet essential requirements of air space and recreation. Economic solutions of these problems largely resolve themselves into questions of transport and land prices. The reduction of costs of transport involves the elimination of unnecessary travel, and the reduction of land prices the elimination of values based on improper or unhealthy uses of land.

The need for scientific investigation of the excess concentration as a first step for a national effort towards its control was stressed by Dr. Adams. Other research is needed to ascertain the best methods of reducing 'friction of space' between producers and consumers of goods and services, and between places of residence and places of work and recreation. 'Town planning should bo based more on the data of the economist and less on the consideration of sentimental values.

Among the major defects in urban growth, Dr. Adams directed attention to the obstruction of the movement of street traffic and the absence of space for standing traffic, as well as to the overcrowding of facilities for passenger traffic and the resultant destruction of nervous energy. He also stressed the overerowding of population on the land, thus pre. venting the inhabitants from securing adequate light, air and recreation, and the absence of room for the expansion of industrial plants, markets, etc. Such ovils cannot be remedied effectively by the negative process of planning control. Dr. Adams suggested that the ratio of open space in a town for traffic, recreation and space about buildings should not be less than sixty per cent.

\section{CONFERENCE OF LEATHER CHEMISTS}

$\mathrm{D}$ ESPITE the uncertain conditions which prevailed, the Biennial Conference of Leather 'Trades' Chemists was held in London during August 28-30. The Conference was preceded by a reception of members of the International Society of Leather Trades' Chemists and numerous foreign guests at the May Fair Hotel, London, on Sunday, August 27, when they were received by the president of the British Section, MIr. R. Faraday Innes.

At the opening meeting, the first Procter Memorial Lecture was delivered by Dr. W.T. Astbury, the title being "The Molecular Structure of Fibres of the
Collagen Group". The presidential address given by Mr. W. R. Atkin was on the subject of "The Procter Wulson Theory of Protein Swelling in the Light of Modern Ideas of Protein Structure". Prof. P. Chambard of Lyon was elected president of the Society for $1940-11$.

During the meeting, it was announced that the Fraser Muir Moffat IIedal of the Foundation of 'Tanners' Research Laboratory of America had been awarded to Dr. Dorothy Jordan Lloyd for her out. standing work in the field of tanning chemistry, and particularly her recent book on "The Chemistry of 
the Proteins". Among other papers read during the meeting were, "A New Expression for the Buffering Capacity of Solutions" by Dr. V. Kubelka (Brno), "Fatty Spue in Semi-Chrome Leather" by R. Faraday Innes (London), "Studies in Currying" by M. P. Balfe (London), "Precipitation of Natural Tannins with Calcium Hydroxide" by Vl. Němec (Brno), Conductimetric Analysis of Vegetable Tanned Jeathers" by S. G. Shuttloworth (South Africa), "Formaldehyde Tannage in Relation to the Constitution of Collagen" by F. O'Flaherty (U.S.A.),
"The Chemistry of Formaldehyde Tanning" by Miss IV. B. Pleass and Miss J. H. Boows (London), "Reaction between Casein and Formaldehyde" by C. Robinson (London), "A Machine for Measuring the Resistance of Leather to Abrasion" by F. E. Humphreys (London), "Shoo Troubles and Loather Faults" by H. Bradloy.

Before the conclusion of the Conference, the following films were shown: "The Inside Story of Lubrica. tion", "Wattle Bark and Extract Manufacture" and "Preparation of Cod Liver Oil".

\section{PROGRESS OF}

$\mathrm{D}^{\mathrm{n}}$ R. H. W. MELVILLE prepared an evening lecture for the Dundeo meeting of the British Association, under the title "Now Lamps for Old" The natural illuminant, the sun, is considered first. We may regard tho sun as a 'black body' with a surface temperature of about $6000^{\circ} \mathrm{C}$. Being a black body, it emits light of all wave-lengths, but the wave-lengths in which wo aro particularly interested lie in the visible region from about $4000 \mathrm{~A}$. to $7500 \mathrm{~A}$., for it so happens that evolutionary processes have developed a human optical system which is most sensitive to such a band of wave. lengths.

When we measure the energy emitted by the sun within a small band of wave-lengths, for example, $10 \mathrm{~A}$., and plot the energy as a function of the wavelength of this band of radiation, wo obtain a curve with a pronounced maximum at about $5500 \mathrm{~A}$., in the green. Again, the human eye is most sensitive in the region where the sun emits this maximum. Besides radiation in the visiblo region, there is also radiation at longer wave-lengths in the infra-red and at shorter wave-lengths in the ultra-violet. These radiations cannot be perceived by the human eye, but they can be detected by various physical methods.

It would seem, then, that the production of artificial illumination exactly similar to that of the sun is a simple matter. All wo need do is to heat something black to a temperature of $6000^{\circ} \mathrm{C}$. But the difficulty is that we cannot devise a means of heating a substance to this temperature, as all known materials either melt or volatilize so quickly that the conditions cannot be realized. Our problem, therefore, is to devise some subterfuge which will get over the difficulty without having to resort to the drastic method of getting radiation similar to that obtained from the sun. As a matter of interest, there is a possibility of doing better than tho sun does. So far as illumination is concerned, the infrared and ultra-violet radiation is wasted. If the energy of these rays could be converted into visible radiation, the efficiency of our source would be appreciably increased.

Tho goal to be obtained in the search for the ideal source of light is one in which all the energy supplied to the lamp, in whatever form, is wholly converted into visible radiation, with precisely the samo intensity and wave-length distribution as that given by the sun. Dr. Melville gives an account of the progress that has been made torards this goal and how far we have still to go.

\section{ILLUMINATION}

More than four thousand years ago, it was observed that certain vegetable and perhaps mineral oils, on undergoing combustion, emit visible radiation. 'Then by using a lamp into which a wick dipped, the burning was easily controlled at the top of the wick. Hero then is the first principlo of the subject-the conversion of oil into vapour and the subsequent combustion of the vapour. The next development was gas lighting. This phase occurred when it was found that oil could easily bo converted into gas, and later when coal was found to undergo a similar reaction.

By allowing a substanco to undergo combustion, a sufficiently high temperature is generated to produce visible radiation. If, therefore, wo are going to increase the efficiency of our source of light, we must find out what produces the light. An experiment answers this question. The flame of a mixture of hydrogen and carbon monoxide emits only a small amount of radiation in the blue. When the gas is diverted through a bottle containing finely divided carbon, the flams becomes luminous and on close examination the incandescent particles of carbon can be seen describing vortices in the flame itself. The luminosity of the usual gas flame is thus due to carbon. The origin of the carbon in the gas flame is the decomposition of the volatile hydrocarbons present in the coal gas.

The temperature of even finely divided carbon in such a flame is only $1100^{\circ} \mathrm{C}$., and therefore its colour does not approach that of the sun. Bunsen improved this by mixing the gas with air and by increasing its pressure. When mantles made of thorium and cerium are used, tho light is the lyightest. The curves obtained by the so-called Welsbach mixture show that the temperature attained is the highest. The light obtained from an ordinary gas mantlo has a distinctly greenish tinge. This proves that it is no longer similar to a black body at the same temperature.

Besides the luminescence emitted by hot interacting gases, there are a number of solid and liquid reactions in chemistry which are accompanied by luminescence at ordinary temperatures. The luminescence of a firefly is a familiar example, but the precise nature of the reaction is not known. Unfortunately, one firefly gives only $1 / 1600$ candle power, mostly in the green and red. For lighting a lecture room of reasonable size, about a million fireflies would be required.

Finally, the electrical methods of producing radiations are considered. The first attempts were 